\title{
SPATIAL ACCESSIBILITY OF URBAN PARKS IN TANGIER CITY, MOROCCO
}

\author{
M. Maliari ${ }^{1}$, A. Azyat ${ }^{1}$, N.B. Achhab ${ }^{1}$, N. Raissouni ${ }^{1}$, A. Chahboun ${ }^{1}$ \\ ${ }^{1}$ RSGIS Lab, Remote Sensing GIS Unit, Tetuan, Morocco - (mohammedmaliari@gmail.com, azyat.ensat@gmail.com, \\ aworld.nizar@gmail.com, raissouni.naoufal@gmail.com,chahboun_asaad@yahoo.fr)
}

KEY WORDS: Urban Parks, Public Health, GIS, Distribution of Urban Parks, Green Space, Urban Environment.

\begin{abstract}
:
Recently, Urban Parks presents an essential role of humanity, because they provide a many of benefits that support our physical and social health. Therefore, UP (Urban Parks) are crucial part of whole urban environment. In this paper, we present the role of Green Space in public health, and based on Geographical Information System (GIS) techniques, we will start our study with a case study of the city of Tangier in northern Morocco. The city has had remarkable development in recent years. So, the inhabitants of Tangier need demands in the public services, in particular the urban parks.So we studied the distribution of urban parks in the different commons of the city (Tangier, Charf, Benimakada and Boukhalef (Guezania previously)) by calculating the area and the number of UPs in each common, then a calculation on the indices (PAC, PAR and PR ) for each region, and finally make a comparison with the situation in 2015 .
\end{abstract}

\section{INTRODUCTION}

In the world, we can observe phenomena of urbanization almost everywhere. Usually, urbanization goes hand in hand with the industrial economic development of a region or country. In search of more favorable economic development, many populations are moving to the cities.

Rapid urbanization has caused changes, such as increased traffic, air and water pollution, decrease in agricultural land and space, and anthropogenic climate change. These changes threaten human health and the quality of life (Song et al., 2015). Indeed, this urbanization phenomenon has influences, such as urban changes and development, which have some environmental impacts on Urban Green Spaces (UGS) (Azyat et al., 2019). Green spaces play a very important role in urban areas. The presence of green spaces seems to be associated with several significantly positive effects on the environment and on the physical and mental health of the population. Trees reduce pollutants, such as dust, ozone, and heavy metals. Green spaces also reduce noise, local temperature and the effect of urban heat islands. In addition, several studies suggest that urban green spaces are associated with better self-reported and diagnosed health, better level of physical activity, lower mortality rate, and fewer psychological symptoms, less anxiety, depression and stress. , and a greater level of social coherence. In addition, some studies suggest that these links are stronger among the most disadvantaged population groups. Although future studies will be needed in order to refine the analysis of the observed relationships, it seems that green spaces are very important for urban health and should be considered as a central element during urban planning.

According to the 2019 census, the city of Tangier has approximately $1,065,601$ inhabitants. However, this wave of population increase in Tangier has influences, such as urban changes resulting in the degradation of urban parks, and the tendency to be densely built. Therefore, the expansion of SKUs remains an urgent necessity for ecological balance.

Therefore, the use of GIS makes it possible to acquire, organize, manage, process and restore geographic data in the form of plans and maps (intuitive and evolving cartography), in order to study the evolution of UGS in comparison with the increase in population and the densely built.

\section{THE RELATIONSHIP BETWEEN PUBLIC HEALTH AND GREEN SPACESTITLE}

Today, Green spaces are one of the most important spaces in urban areas. Parks plays a multi-purpose role in urban areas that provides social, economic and Environmental benefits (Saleemet al., 2014). Their presence is associated with several positive effects on the environment and on the physical and mental health of the population. The distance from home to the parks has impact on the frequency of use people have a strong belief in the possible outcomes related to health that may result from the open space (Saleemet al., 2014).

Green spaces reduce pollutants (dust, ozone and heavy metals etc.), and noise as well the local temperature. However, green spaces lead to better health, better physical activity, less depression and less stress.

Note that a mature tree provides oxygen for four people.

Airborne particles are among the components of air pollution that have damaging effects on health. Trees, like plants, trap airborne dust until it falls to the ground in rain showers. Ozone is also a pollutant with harmful effects on health. In urban areas, it becomes essential to reduce the ozone level, particularly in the most polluted regions (Vida, 2011).

Modern urban life style is associated with chronic stress. Urban green spaces, such as parks, playgrounds, and residential greenery, can promote mental and physical health, and reduce morbidity and mortality in urban residents by providing psychological relaxation and stress alleviation, stimulating social cohesion, supporting physical activity (Egorov et al., 2016).

Green spaces have effects on mental health, A Dutch study (de Vries et al., 2003); described previously, found that a greater proportion of green spaces close to home is associated with significantly higher scores. Low on the General Health Questionnaire, which primarily measures psychological distress. Although greater distress is observed in urban settings, the impacts of green spaces made the effect of urbanization insignificant, indicating that the amount of green space is more 
strongly related to mental health than it is. the level of urbanization. The authors hypothesised that greenness would be more indicative of mechanisms involving reduction of psychophysiological stress, and modifying the impact of air pollution, noise and temperature, while proximity to a major green space would be more indicative of mechanisms involving physical activity (Egorov et al., 2016).

\section{METHODOLOGY}

\subsection{Study area}

Tangier is a city in northern Morocco, the second economic heart of Morocco, and capital of the Tangier-Tetouan-Al Hoceima region. Its position is a point of the junction between the Mediterranean Sea and the Atlantic Ocean. The city has experienced remarkable development in recent years in all areas (industrial, commercial and demographic).

However, the inhabitants of Tangier need demands in the public services, in particular the urban parks. The population of Tangier amounted to $1,065,601$ inhabitants in the 2015 census with a study area of $233.67 \mathrm{~km}^{2}$. The study area includes 4 commons (Tanger-Medina, Charf-Sounani and Charf-Mghogha, Benimakda, Boukhalef(Gueznaia)).

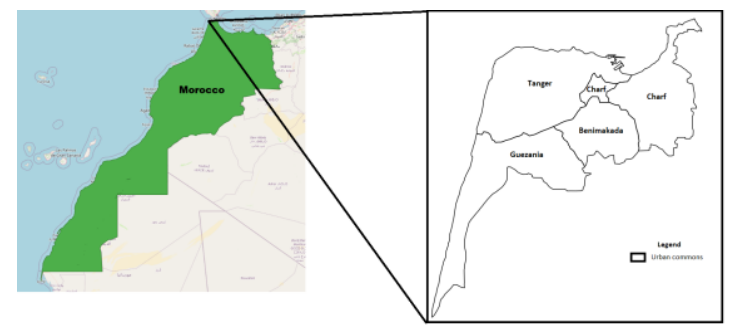

Figure 1. Tangier city localization

\subsection{Data sources and preparation}

For our work, we are based on the use of GIS. The GIS (Geographic Information System) offers all the possibilities of databases, through a unique visualization and geographic analysis specific to the maps.

Everyone uses GIS: local authorities, public sector, business, schools, administrations, states use Geographic Information Systems (GIS). The creation of maps and geographic analysis are not new processes, but GIS provides greater speed and offers constantly innovative tools in the analysis, understanding and resolution of problems.

With regard to measuring inhabitant's needs towards UP, researchers and planners have been implementing GIS for managing, planning and treating concerns of spatial distribution. Thereby, lot of GIS-based researches have been adopted in order to analyze and assess green spaces and UP in different ways (Azyat et al., 2019).

To study a spatial distribution (Fig 2), we must apply calculations on the zones and the UP indices in order to verify the surface and the location of each park is satisfactory in relation to the surface of each common and the number of inhabitants.

However, the UP indices defined in order to assess the characteristics of the UP. The work is based on the diversity and spatial distribution of the UP, aimed at meeting satisfaction and efficiency in the city.
For this, three indices were considered: the area of the park per inhabitant (PAC), the ratio of the area of the park (PAR) and the population ratio (PR) (Azyat et al., 2019). It should be noted that the UP indices refer to the estimation of the sufficiency and accessibility with respect to the population based on the UP spatial distribution.

The UP situation 2021 spatial distribution study is analyzed by QGIS 3.18.1 software. The UP include different parks for each common in the city of Tangier. Knowing that we have four commons: Tangier, Charf, Benimakada and Gueznaia. Each common has a number of parks, either neighborhood parks or parks managed by the authority. Figure 2 shows the accessibility of the UP in the city of Tangier for each common. From Fig. 1, we remarked that the UPs are distributed without any regulations/standards, and their sizes do not follow any formulas. They are rare in some places (Azyat et al., 2019).

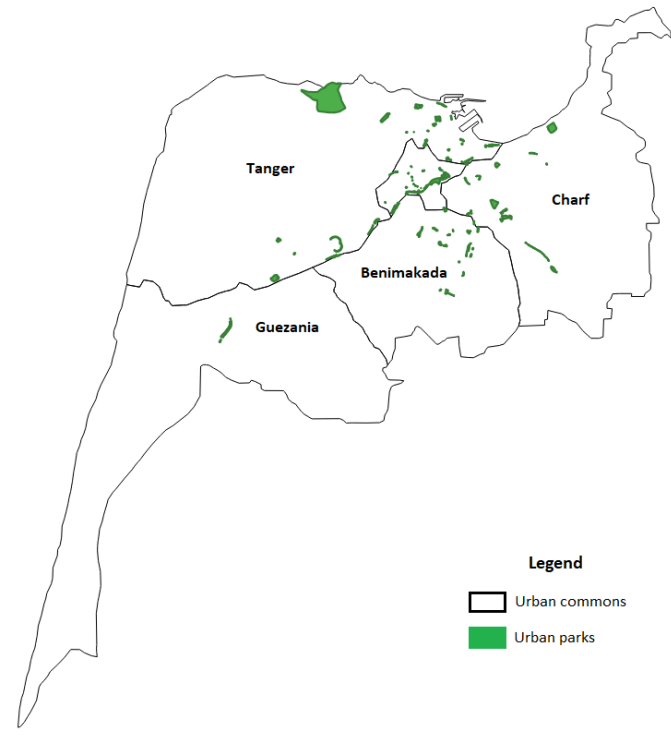

Figure 2. Spatial Distribution of urban park

\subsection{Urban Parks classification and accessibility}

Public Urban parks and open space could be classified into five types according to NRPA. The Tangier urban park types are as follows (see Table 1): Mini-park, Neighborhood parks, Community parks, Regional parks, and City parks. Table 1 illustrates the ideal guidelines in terms of the location and size of open park types relatively to the residents. This table describes parks classification in conjunction with access and area criteria. Inventory of Tangier urban park sites, the parks were categorized into five classifications in accordance to NRPA definitions. The following urban park classifications are briefly described.

- Mini-parks: they form the small spaces that serve isolated community within an immediate locality. Generally, its average is about 0.5 ha or less in size. Due to their small size, they offer limited services and accessibility radius is $200 \mathrm{~m}$.

- Neighborhood parks: they are between mini-parks and community parks providing similar features within walking distance of residential areas. They are more than 0.5 and lesser than 2 ha in size and the distance of accessibility is $600 \mathrm{~m}$.

- Community parks: They should be easily accessible by all inhabitants within radius of accessibility is $1200 \mathrm{~m}$. Usually, their size are 2 to 4 ha. In addition to, each community park should be available to the entire community. 
- Regional park: generally, they are much bigger than a community park in size, and its accessibility distance is $2500 \mathrm{~m}$. - City parks: they are created for all urban residents and are more than 10 ha in size with several recreation amenities. The accessibility is a 30-min drive or more.

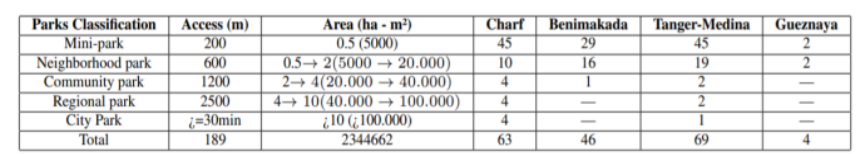

Table 1. The Tangier urban park types

\subsection{Data analysis: Spatial Indices}

In order to provide the population of a city with access to healthy environments and living environments, in order to walk to green spaces, a recommendation was to develop an indicator based on the analysis of GIS data on the land use and population reflecting the proximity of the population to urban green spaces (Egorov et al., 2016).

Green space usage may be physically active or passive, and could lead to health and well-being benefits through various mechanisms (Egorov et al., 2016).

Urbanization has effects on environmental components, for example the diversity of green spaces (size, quantity of parks, types of green spaces, use and spatial distribution of the UP). Certain indices are defined to evaluate the characteristics of UP.Thus, the objective was to answer the question: is this distribution sufficient and efficient or not over the city? For this, three indices have been considered: Park Area per Capita (PAC), Park Area Ratio (PR) and Population Ratio (PR).

These indices are used in order to have the estimation of the sufficiency and accessibility with respect to the area and the population based on the UP spatial distribution (Azyat et al., 2019).

PAC: Represents the total area of parks devised on the total population (the amount of accessible urban park per capita).

\section{$\frac{\text { totalareaofparks }}{\text { totalpopulation }}$}

$\bullet$

PAR: The percentage of parks area within the area of analysis excluding park area.

$$
\frac{\text { populationbypark }}{\text { totalpopulation }} * 100
$$

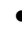

PR: The percentage of population served by the parks in a common.

$$
\frac{\text { populationbypark }}{\text { totalpopulation }} * 100
$$

\begin{tabular}{|c|c|c|c|c|c|c|}
\hline Urban common & UP numbers & Total park area & Population & PAC & PAR & PR \\
\hline Charf & 63 & 536781 & 318250 & 1.68 & 0.84 & 32.9 \\
\hline Benimakada & 46 & 289130 & 385922 & 0.74 & 0.81 & 39.89 \\
\hline Tanger & 69 & 1477045 & 239645 & 6.16 & 1.94 & 24.77 \\
\hline Guezania & 4 & 31.355 & 23475 & 1.33 & 0.04 & 2.42 \\
\hline Total & 182 & 2344662 & 967292 & & & \\
\hline
\end{tabular}

Table 2. Up Numbers And Indices (Park Area Per Capita, Pac (in $\mathrm{m}^{2}$ ), Park Area Ratio, Par (In $\backslash \%$ ), Population Ratio, Pr (in 1\%)) For The Four Commons; Tanger, Boukhalef, Charf And Benimakada. (Situation 2021)

\begin{tabular}{|c|c|c|c|c|c|c|}
\hline Urban common & UP numbers & Total park area & Population & PAC & PAR & PR \\
\hline Charf & 12 & 192875 & 318679 & 0.61 & 0.65 & 32.61 \\
\hline Benimakada & 3 & 31545 & 386191 & 0.08 & 0.03 & 39.75 \\
\hline Tanger & 5 & 1479952 & 243082 & 6.08 & 2.06 & 25.02 \\
\hline Boukhalef & 2 & 48928 & 23601 & 2.07 & 0.03 & 2.43 \\
\hline Total & 22 & 1753300 & 971553 & & & \\
\hline
\end{tabular}

Table 3. Up Numbers And Indices (Park Area Per Capita, Pac (in m2), Park Area Ratio, Par (in 1\%), Population Ratio, Pr (in 1\%)) For The Four Commons; Tanger, Boukhalef, Charf And Benimakada. (Situation 2015)

Table 2 and 3, shows the number of existing parks for the 2021 and 2015 situation, their area and their ratio.

For the 2021 situation, the study area contains 182 UP with a total area of $2,34 \mathrm{~km}^{2}$, like the situation in 2015 , the majority of these UPs are concentrated in the common of Tangier with 69 parks of different sizes.

For the common of Charf, contains 63 parks, it is the second common that contains the highest number of UPs, which are consists of two parts: Charf-Souani \& Charf-Mghogha.

However, this common has the largest park (Rmilat Park) with an area of $1.06 \mathrm{~km}^{2}$, this UP is defined including the natural one managed by the authority. The least is the commune Guezania with 4 UP.

We had a name change about the common Boukhalef (Situation 2015) and Gueznaia (Situation 2021), they are the same commune.

On the basis of Table 2, a comparison of the indices of urban parks must be made. As in the situation of 2015, still the highest PR is in the common of Benimakada (39.891\%), the lowest also in the common of Gueznaia (2.421\%). For the terms of PAC and PAR, the common of Tangier has the highest value of $6.16 \mathrm{~m}^{2}$ and $1.941 \%$, while, the lowest value is recorded in the common of Benimakada with $0.74 \mathrm{~m}^{2}$, but for the PAR indice, the lowest value concerns the common of Gueznaia with $0.041 \%$.

(Note: The common of Guézania is not in table 2, because the period between 2015 and 2021 the authorities of tangier changed the name of this common to Boukhalef.

In our case, the parks accessibility with social group factor is analyzed using buffer method.

All data on parks, use Google satellite maps using a QGIS tools. The operation is to add the google satellite layer in QGIS, which allows us to visualize the Earth with an assembly of aerial or satellite photographs, which gives a quality vision of the location of urban parks.

Then, we must look for the new urban parks, and then add them as polygonal entities, and of course, to specify the common it belongs to. Finally, use the field calculator, which calculates the area of each feature to add.

\section{RESULTS AND DISCUSSION}

Today, the number of built-up areas is growing to population rate and has increased in city of Tangier by fast urbanization and industrialization over recent years.

Urban parks have a strategic importance for the quality of life in Tangier urban society and play a significant role in increasing the livability of cities.

Urban green spaces and recreational land uses are perceived to have effects on social cohesion, as all groups of people are 
related to nature regardless of their social status (de Vries et al., 2003).

In addition to the psychological benefits from contact with nature, there are also direct physical health benefits, such as addressing issues associated with obesity, increased longevity, and self-reported health (Pretty et al., 2005).

Health and well-being benefit may be gained without actual physical use of green space; for example, there may be psychological effects of simply viewing green space, even if it is not publicly accessible (private gardens). However, several of the pathways from green space to health and well-being require that individuals actually spend time in the green space in order to gain benefit (Egorovet al., 2016).

These indicators may help to provide information on, for example, green spaces that are underutilized or that have potential for diversification of use and users. There are several ways in which usage might be measured (Egorovet al., 2016).

\subsection{Urban parks distribution and levels of accessibility}

Urban parks are potentially important, are places of recreation, depression for the people of Tangier. However, 182 parks in total. The analysis shows that the distribution of the parks does not show the accessibility of the population. Indicators of green space accessibility take into account the distribution of the population (individuals, households or communities) in terms of their proximity to green space. They may also include consideration of whether the green space is publicly accessible, and if so, where access points and routes are located (Egoroy etal., 2016). On the other hand, the distribution of parks shows that several districts of the city have poor accessibility to parks (Figure 2).

Many studies of green space and health have used proximity metrics to estimate accessibility of green spaces.

For example, taking the common of Benimakada, with the population number of 385,922, (the largest number of population in the whole city) and a total number of urban parks 46. Then, according to Table 1 , the urban parks of the common of Benimakada does not have a large area, however, what can be said that the majority of these parks are small neighborhood parks. While other towns (Charf and Tangier) have less number of inhabitants, with a larger number of urban parks and of course a large area, and the largest city parks are in the common of Tangier. Therefore, the common of Benimakada suffers from a deficiency in relation to the distribution of urban parks comparing to other commons.

Not all city dwellers have access to parks and green spaces. Consequently, in addition to being concerned with the whole number of communes having green spaces, the decision-makers must take into account the problems of these distributions and the very great distances. For example, Park Rmilat is located in the municipality of Tangier; it is the largest park in the city, so the population of certain commons have difficulty in moving to the park because of the distance.

In addition, the distance-based measures of access could be refined to include travel constraints, such as physical and psychological barriers to pedestrian movement (de Vries et al., 2003).

\section{CONCLUSION}

Green spaces play a very important role in living a very calm, stress-free life. In the present study, we assessed the spatial distribution of urban parks and their positions in a Moroccan city that undergoes a very large Tangier assessment. The study of this evolution is made in relation to the distribution of urban parks in each municipality of Tangier, and the number of inhabitants.

Make a comparison between the different commons, in relation to their area, the number of urban parks in each municipality.

Three indices; park area per capita, park area ratio and population ratio have been calculated to measure the accessibility and the sufficiency relative to UP.

According to our study, several negative points were revealed, the first is the number of parks is really insufficient in the four commons.

\section{ACKNOWLEDGEMENTS}

Acknowledgements of support for the project/paper/author are welcome if they do not violate the anonymity of the submitted paper. Otherwise, they should be masked.

\section{REFERENCES}

Azyat, A., Raissouni, N., Achhab, N. B., Chahboun, A., Lahraoua, M., Elmaghnougi, I., Sebbah, B., Ismaili, A., 2019.Urban Parks Spatial Distribution Analysis and Assessment Us-ing GIS and Citizen Survey in Tangier City, Morocco (2015Situation).Advanced Intelligent Systems for Sustainable Devel-opment (AI2SD’2018)., 915, 609-621.

de Vries, S., Verheij, R. A., Groenewegen, P. P., Spreeuwen-berg, P., 2003. Natural environments healthy environments? Anexploratory analysis of the relationship between greenspace andhealth.Environment and Planning A: Economy and Space., 35,17171731.

Egorov, A. I., Mudu, P., Braubach, M., Martuzzi, M., 2016.Urban green spaces and health.

Pretty, J. N., Bragg, R. E., Barton, J., 2005. The mentaland physical health outcomes of green exercise.InternationalJournal of Environmental Health Research., 15, 319-337.

Saleem, A., Ijaz, S., Igarashi, M., 2014. A GIS Based Measurement of Accessibility of Urban Parks in Faisalabad City,Pakistan.Academic Research International., 5.

Song, C., Ikei, H., Igarashi, M., Takagaki, M., Miyazaki, Y.,2015. Physiological and Psychological Effects of a Walk inUrban Parks in Fall.Int. J. Environ. Res. Public Health 2015.,12, 14216-14228.

Vida, S., 2011. Les espaces verts urbains et la sant' e.Institutnational de sant e publique du Qu'ebec., 16. 